\title{
Disseminated Candida infection syndrome in heroin addicts-dominance of a single Candida albicans biotype
}

\author{
F. C. ODDS, AMALIA PALACIO-HERNANZ," J. CUADRA† and J. SANCHÉZ†
}

\begin{abstract}
Department of Microbiology, University of Leicester, Leicester LE1 7RH, "Hospital $1^{\circ}$ de Octubre, Madrid, Spain, and † Departmento de Dermatología, Hospital General Valèncía, Spain
\end{abstract}

\begin{abstract}
Summary. Among 21 intravenous heroin abusers with cutaneous and ocular manifestations of disseminated Candida infection, a single $C$. albicans strain type (serotype A, biotype $15^{3} / 7$ ) was isolated from skin lesions in 14 cases. This suggests that central contamination of the heroin with C. albicans is less likely to be the source of infection than an endogenous source, and that one particular strain type is either better adapted than others to grow in the lemon juice used as a heroin solvent, or more likely than others to cause the specific pathology seen in these patients.
\end{abstract}

\section{Introduction}

There is now an extensive literature on a specific syndrome of disseminated Candida infections in heroin addicts. The infections are characterised by several features, of which chorioretinitis and follicular and nodular skin lesions are the most common, and associated in some instances with costochondral arthritis (Barthelemy et al., 1981; Dally et al., 1982; Mellinger et al., 1982; Badillet et al., 1983; Collignon and Sorrell, 1983; Dally et al., 1983; Drouhet and Dupont, 1983; Hoy and Speed, 1983; Mackay, 1983; Tápies Barba et al., 1983; Cuadra et al., 1984; Dupont and Drouhet, 1985; Servant et al., 1985). C. albicans has been isolated almost invariably from the cutaneous lesions, but rarely cultured from the blood or vitreous fluid. The sources of the fungus in these cases remain uncertain. Although some authors have suggested that $C$. albicans may contaminate brown (street) heroin (Mellinger et al., 1982; Dally et al., 1983), attempts to culture $C$. albicans from the heroin involved have been unsuccessful (Mellinger et al., 1982; Dally et al., 1983; Dupont and Drouhet, 1985; Servant et al., 1985; Shankland et al., 1986), and there is evidence that heroin inhibits the growth of C. albicans in vitro (Dupont and Drouhet, 1985; Servant et al., 1985; Shankland et al., 1986). The lemon juice used by addicts as a heroin solvent has frequently been postulated as a source (Hoy and Speed, 1983; Mackay, 1983; Newton-John et al., 1984; Servant et al., 1985; Shankland et al., 1986), and Shankland et al. (1986) recovered C. albicans

Received 8 Jul. 1986; revised version accepted 1 Aug. 1986. from the juice in two plastic lemons submitted by addicts. Other postulated sources are use of unhygienic injection techniques (Barthelemy et al., 1981; Badillet et al., 1983) and the direct spread of $C$. albicans from the gut (Dupont and Drouhet, 1985).

So far, no attempt appears to have been made to establish which biotype or biotypes of $C$. albicans have been involved in the heroin-associated infections, yet if a single biotype was responsible for all the cases it would be strong evidence in support of a single central source of infection. We have therefore undertaken a survey of $C$. albicans biotypes from cutaneous lesions in 21 Spanish patients with heroin-associated Candida infections.

\section{Patients and methods}

\section{Patients}

The study group comprised 18 male and three female heroin abusers, aged 19-33, who had presented at clinics in Madrid or Valencia within the last 2 years. The patients had high fever (not noted in one case only) that within 2-7 days was followed by the development of skin changes. All the patients had nodular or follicular lesions, or both, affecting the scalp. Males frequently had a folliculitis of the beard area. In four cases there were nodular lesions in the pubic area, and one patient had follicular lesions on the neck, chest and arms. There were signs of Candida endophthalmitis in 7 of the 21 patients. Blood cultures for bacteria and fungi gave negative results in all 21 cases; however, all the patients yielded high numbers of $C$. albicans in cultures from the skin lesions. 


\section{C. albicans biotyping}

The C. albicans isolates were biotyped according to the methods of Odds and Abbott $(1980,1983)$. The biotyping tests were repeated on three occasions to ensure consistency of results. From 16 of the patients a single isolate was tested; from the other five, isolates from at least two anatomical sites were tested.

A control group of 45 C. albicans isolates was obtained from the same Madrid clinic that was attended by 12 of the patients with the heroin-associated Candida infection. Clearly, these control isolates could not be obtained from lesions similar to those of the heroin addicts; 43 were from patients with Candida vulvovaginitis, one each from skin and nail lesions.

\section{Results}

Fourteen $(67 \%)$ of the 21 patients with heroinassociated disease were infected with $C$. albicans biotype $15^{3} / 7$. The other seven were types 075,135 , $137,175,253,557$ and one indeterminate type. All the isolates were serotype $A$ and all could use citrate as a carbon source. In the three cases where isolates were obtained from different anatomical sites, all the isolates were type $15^{3} / 7$. The prevalence of biotype $15^{3} / 7$, serotype A strains in the control isolates was $11 \cdot 1 \%$ ( 5 out of 45$)$. Thirteen $(28.9 \%)$ of the control isolates were serotype $\mathrm{B}$; these did not include any examples of biotype $15^{3} / 7$.

\section{Discussion}

These results indicate a greatly heightened prevalence of $C$. albicans biotype $15^{3} / 7$ in patients with heroin-associated Candida infection that may be accounted for in two ways. First, the source of the fungus could be the heroin itself or its acid solvent; second, type $15^{3} / 7$, serotype A, whatever its source, may have a higher predilection for causing infection than other biotypes of C. albicans. If the heroin were the source, it is difficult to understand why some of the isolates were not biotype $15^{3} / 7$. The idea of contamination of the lemon juice solvent, either for individuals injecting their heroin alone or for small groups sharing lemon

\section{REFERENCES}

Badillet G, Pietrini P, Puissant A 1983 Pustuloses chez des héroïnomanes. Annales de Dermatologie et Venereologie 110 : 691-692.

Barthelemy F, Offret H, Saragoussi J J, Pouliquen Y, Dhermy P 1981 Toxicomanies et endophthalmies à Candida albicans: problèmes diagnostiques et thérapeutiques. Journal Français d'Ophthalmologie 4: 637-646.

Burnie J P, Odds F C, Lee W, Webster C, Williams J D 1985 juice, is entirely compatible with our results and with the observations that $C$. albicans grows well in fresh lemon juice (Newton-John et al., 1984) and can sometimes be recovered from lemon juice used by addicts (Shankland et al., 1986). It is notable that all the isolates from the addicts gave positive results in the citrate biotyping test, indicating their ability to grow on citrate at a low $p \mathrm{H}$ value (Odds and Abbott, 1980).

C. albicans type $15^{3} / 7$ is closely related to a type $(\% / 15 / 7)$ previously found to be responsible for an outbreak of systemic Candida infection in a hospital intensive care unit and to possess an enhanced ability to adhere to epithelial cells (Burnie et al., 1985). Its isolation in the majority of cases of the Candida-heroin addiction syndrome is, therefore, compatible with the possibility of endogenous infection of the addicts. C. albicans is a ubiquitous member of the normal human microflora, and it is evident from the control isolates in this study that type $15^{3} / 7$ is a common biotype amongst vaginal isolates. A previous survey showed that the frequencies of different $C$. albicans biotypes are similar regardless of their anatomical site of isolation, and that types 153 and 157 belong to the most numerous group of C. albicans biotypes (Odds et al., 1983). The $11 \%$ prevalence of type $15^{3} / 7$ in vaginal isolates is, therefore, likely to indicate the normal prevalence of this type in other sites, including the gutnormally held to be the major human reservoir of C. albicans.

In the absence of prospectively gathered data concerning Candida colonisation of heroin addicts with and without the systemic Candida infection syndrome we conclude that candidaemia may be a common sequel to intravenous heroin usage, either directly or indirectly (via lemon juice) from a reservoir, presumably endogenous to the user(s) and that $C$. albicans serotype A, biotype $15^{3} / 7$ is more likely to be involved in invasive disease in addicts than are other strain types of the fungus.

We thank Miss B. K. Gill for technical assistance. This work was supported by a grant from the Wellcome Trust.
Outbreak of systemic Candida albicans in intensive care unit caused by cross infection. British Medical Journal 290: 746-748.

Collignon P J, Sorrell T C 1983 Disseminated candidiasis: evidence of a distinctive syndrome in heroin abusers. British Medical Journal 287: 861-862.

Cuadra J, Sánchez J, Aliaga A, Serrano G 1984 Candidiasis in parenteral heroin users: clinicopathologic findings. Archives of Dermatology 120 : 1609-1610.

Dally S, Mellinger M, Thomas G, 1982 Alopecia, blindness and 
skin rash in heroin addicts. Veterinary and Human Toxicology $24: 282$.

Dally S, Thomas G, Danan M 1983 Candidiasis in heroin abusers. British Medical Journal 287: 1549.

Drouhet E, Dupont B 1983 Laboratory and clinical assessment of ketoconazole in deep-seated mycoses. American Journal of Medicine 74, suppl Jan 24: 30-47.

Dupont B, Drouhet E 1985 Cutaneous, ocular and osteoarticular candidiasis in heroin addicts: new clinical and therapeutic aspects in 38 patients. Journal of Infectious Disease 152: 577-591.

Hoy J, Speed B 1983 Candidiasis in heroin abusers. British Medical Journal 287 : 1549.

Mackay M 1983 Candidiasis in heroin abusers. British Medical Journal 287: 1885.

Mellinger M, DeBeauchamp O, Gallien C, Ingold R, Tabaoda M J 1982 Epidemiological and clinical approach to the study of candidiasis caused by Candida albicans in heroin addicts in the Paris region: analysis of 35 observations. Bulletin on Narcotics 34: 61-81.

Newton-John H F, Wise K, Looke D F M 1984 Role of the lemon in disseminated candidiasis of heroin abusers. Medical Journal of Australia 140: 780-781.

Odds F C, Abbott A B 1980 A simple system for the presumptive identification of Candida albicans and differentiation of strains within the species. Sabouraudia 18: 301-317.

Odds F C, Abbott A B 1983 Modification and extension of tests for differentiation of Candida species and strains. Sabouraudia 21 : $79-81$.

Odds F C, Abbott A B, Stiller R L, Scholer H J, Polak A, Stevens D A 1983 Analysis of Candida albicans phenotypes from different geographical and anatomical sources. Journal of Clinical Microbiology 18 : 849-857.

Servant J B, Dutton G N, Ong-Tone L, Barrie T, Davey C 1985 Candidal endophthalmitis in Glaswegian heroin addicts: report of an epidemic. Transactions of the Ophthalmological Society of the UK 104: 297-308.

Shankland G S, Richardson M D, Dutton G N 1986 Source of infection in candida endophthalmitis in drug addicts. British Medical Journal 292: 1106-1107.

Tápies Barba A, Garcés Jarque J M, López Colomés J L, Drobnic L 1983 Endoftalmitis por Candida secundaria al consumo de heroína intravenosa. Medicina Clinica (Barcelona) 81 : 674-675. 